\title{
A NEUTRALIDADE DA LEI No 12.973/2014 NA TRIBUTAÇÃO DO LUCRO: UMA ANÁLISE DA ALÍQUOTA TRIBUTÁRIA EFETIVA (ETR) EM COMPANHIAS BRASILEIRAS
}

\author{
THE NEUTRALITY OF LAW No. 12,973/2014 IN TAXATION OF \\ PROFIT: AN ANALYSIS OF THE EFFECTIVE TAX RATE (ETR) IN \\ BRAZILIAN COMPANIES
}

\author{
LA NEUTRALIDAD DE LA LEY No 12.973/2014 SOBRE LA \\ TRIBUTACIÓN DEL BENEFICIO: UN ANÁLISIS DE LA TASA \\ IMPOSITIVA EFECTIVA (ETR) EN EMPRESAS BRASILEÑAS
}

\author{
André de Magalhães Bravo ${ }^{1}$ \\ Otávio Finessi Júnior ${ }^{2}$ \\ Alexandre Gonzales ${ }^{3}$ \\ Artigo recebido em dezembro de 2020 \\ Artigo aceito em maio de 2021
}

\begin{abstract}
RESUMO
A introdução das normas internacionais de contabilidade no Brasil se fez com o compromisso, expresso em lei, de neutralidade tributária. O presente estudo teve por objetivo observar se tal compromisso se efetivou na prática, mediante a comparação da alíquota tributária efetiva (effective tax rate - ETR) dos tributos incidentes sobre o lucro nos períodos de 2010 a 2014, no qual vigorou o Regime Tributário de Transição - RTT, e de 2015 a 2019, já na vigência das regras tributárias atuais, instituídas pela Lei $\mathrm{n}^{\circ} 12.973$, de 13 de maio de 2014. O trabalho teve como base os dados das sociedades anônimas de capital aberto disponível no sítio da Comissão de Valores Mobiliários, agrupados por setores de atividade econômica. Na análise estatística, foi utilizado o software SPSS e aplicados os testes de Kolmogorov-Smirnov e de Wilcoxon. O resultado indicou que não houve alteração estatisticamente significativa nas alíquotas tributárias efetivas para as empresas dos setores de comércio, indústria, serviços e exploração de imóveis. Todavia, no setor financeiro observou-se uma redução estatisticamente significativa das alíquotas tributárias efetivas, mesmo tendo havido no período analisado aumento das alíquotas nominais dos tributos incidentes sobre os lucros das companhias desse setor, o que indica a necessidade de aprofundamento da pesquisa visando identificar a causa desse resultado discrepante.
\end{abstract}

Palavras-chave: Alíquota tributária efetiva. Alíquota tributária efetiva de longo prazo. Lei 12.973. Regime Tributário de Transição.

\footnotetext{
${ }^{1}$ Pontifícia Universidade Católica de São Paulo-SP. E-mail: andre.mbravo@ @otmail.com.

${ }^{2}$ Pontifícia Universidade Católica de São Paulo-SP. E-mail: ofineis@uol.com.br.

${ }_{3}^{3}$ Pontifícia Universidade Católica de São Paulo-SP.E-mail: agonzales@pucsp.br.
} 


\begin{abstract}
The International Financial Reporting Standards (IFRS) were introduced in Brazil with the commitment of tax neutrality. The present study aimed to observe whether such commitment was carried out in practice, by comparing the effective tax rate (ETR) of taxes levied on profits in the periods from 2010 to 2014, in which the transitory tax regime called Regime Tributário de Transição RTT was observed, and from 2015 to 2019, within the application of the current tax rules, established by Federal Law 12,973 of May 13, 2014. The study was based on data from publicly held corporations available on the Securities and Exchange Commission of Brazil's website, grouped by sectors of economic activity. In the statistical analysis, the SPSS software was used and the KolmogorovSmirnov and Wilcoxon tests were applied. The result showed that there was no statistically significant change in the effective tax rates for companies in the sectors of commerce, industry, services and real estate exploration. In the financial sector, there was a statistically significant reduction in the effective tax rate, even though there was an increase in the nominal rates of taxes levied on the profits of companies in this sector within the analyzed period, which indicates the need for further research in order to identify the cause of this discrepant result.
\end{abstract}

Keywords: Effective tax rate. Long-run cash ETR. Law 12,973. Regime Tributário de Transição.

\title{
RESUMEN
}

La introducción de normas internacionales de contabilidad en el Brasil se ha hecho con el compromiso, expresado en ley, con la neutralidad fiscal. El presente estudio tiene por objeto observar si este compromiso fue cumplido en la práctica, comparando la tasa impositiva efectiva (effective tax rate - ETR) de los impuestos sobre los beneficios en los períodos de 2010 a 2014, en los que estaba en vigor el régimen fiscal transitorio llamado Regime Tributário de Transição (RTT), y de 2015 a 2019, ya en presencia de las normas fiscales actuales, establecidas por la Ley No 12.973, de 13 de mayo de 2014. El trabajo se basó en datos de corporaciones que cotizan en bolsa disponibles en el sitio web de la Comissão de Valores Mobiliários brasileña, agrupados por sectores de actividad económica. En el análisis estadístico, se utilizó el software SPSS y se aplicaron las pruebas Kolmogorov-Smirnov y Wilcoxon. El resultado ha indicado que no hubo un cambio estadísticamente significativo en los tipos impositivos efectivos para las empresas de los sectores del comercio, la industria, los servicios y la explotación inmobiliaria. Sin embargo, en el sector financiero se ha observado una reducción estadísticamente significativa de los tipos impositivos efectivos, a pesar de que se ha aumentado el tipo impositivo nominal de los impuestos aplicados a los beneficios de las empresas de este sector, lo que indica la necesidad de profundizar la investigación para identificar la causa de este resultado divergente.

Palabras clave: Tasa impositiva efectiva. Tasa impositiva efectiva a largo plazo. Ley No 12.973. Regime Tributário de Transição.

\section{INTRODUÇÃO}

Os padrões internacionais de contabilidade estabelecidos pelo International Accounting Standards Board - IASB por meio dos International Financial Reporting Standards - IFRS foram introduzidos no panorama jurídico-contábil brasileiro com a edição 
da Lei $\mathrm{n}^{\mathrm{o}}$ 11.638, de 28 de dezembro de 2007, que alterou disposições contidas no artigo 177 da Lei $n^{\circ}$ 6.404, de 15 de dezembro de 1976 (Lei das Sociedades por Ações). Assim, ficou estabelecido no citado artigo 177, a obrigatoriedade de que as normas que viessem a ser expedidas pela Comissão de Valores Mobiliários fossem "elaboradas em consonância com os padrões internacionais de contabilidade adotados nos principais mercados de valores mobiliários" $\left(\S 5^{\circ}\right)$, desvinculando-se da escrituração contábil elaborada para fins societários aquela necessária ao atendimento das exigências da administração tributária $\left(\$ 2^{\circ}\right)$. Estabeleceu-se, ainda, a neutralidade tributária decorrente da adoção das normas internacionais, na medida em que eventuais lançamentos de ajuste necessários à harmonização da contabilidade societária com a contabilidade tributária não poderiam "ser base de incidência de impostos e contribuições nem ter quaisquer outros efeitos tributários" ( $\S$ $7^{\circ}$ ). Dessa forma, como sintetiza Fernandes (2012, p. 132), "restabeleceu-se a distinção entre o registro contábil para fins comerciais e societários e o registro tributário, valendo, para aquele, o padrão internacional de Contabilidade, e, para este, a neutralidade das mudanças contábeis (...)", ressaltando o autor que "(...) a neutralidade tributária foi uma exigência do mercado, especialmente das companhias abertas, para a aceitação dos IFRS como normas contábeis a serem adotadas no Brasil”.

Tais disposições viriam a ser aperfeiçoadas pela Medida Provisória no 449, de 3 de dezembro de 2008, posteriormente convertida na Lei $\mathrm{n}^{\mathrm{o}} 11.941$, de 27 de maio de 2009, criando-se o denominado Regime Tributário de Transição - RTT que, assegurando a neutralidade tributária, teria vigência até que fosse editada lei ordinária regulando o tratamento tributário a ser dado aos lançamentos contábeis decorrentes da adoção dos IFRS. Tal regime, que vigorou facultativamente nos anos de 2008 e 2009 e compulsoriamente de 2010 a 2014, estabeleceu que as alterações no lucro antes dos tributos (LAIR) decorrentes da aplicação de métodos ou critérios contábeis convergentes com as normas internacionais não surtiriam efeitos no Imposto de Renda da Pessoa Jurídica (IRPJ) e a Contribuição Social sobre o Lucro Líquido (CSLL).

Posteriormente, a Lei $\mathrm{n}^{\mathrm{o}} 12.973$, de 13 de maio de 2014, estabeleceu o tratamento fiscal dispensado aos métodos ou critérios adotados ou modificados pela normatização contábil, convergentes com as regras internacionais, sendo obrigatório às pessoas jurídicas submetidas ao lucro real, presumido ou arbitrado no IRPJ e na CSLL a partir de $1^{\circ}$ de janeiro de 2015. A mencionada lei dispôs sobre os ajustes fiscais de adição e exclusão destinados a neutralizar os efeitos tributários decorrentes da aplicação dos pronunciamentos técnicos do Comitê de Pronunciamentos Contábeis (CPC) que já haviam sido publicados à época, reproduzidos em resoluções do Conselho Federal de Contabilidade (CFC) e demais normas dos órgãos reguladores, tais como o ajuste a valor presente (CPC 12), o ajuste a valor justo (CPC 46), o arrendamento mercantil (CPC 06), o ativo imobilizado (CPC 27), a redução ao valor recuperável (impairment) (CPC 01), os investimentos em coligadas e controladas (CPC 18), as combinações de negócios (CPC 15), dentre outros.

Nesse contexto, tem-se o enunciado do problema de pesquisa: considerando os cinco primeiros anos de vigência da Lei $\mathrm{n}^{\circ} 12.973 / 2014$, a tributação sobre o lucro tem sido neutra em relação aos novos métodos e critérios contábeis convergentes com o padrão dos International Financial Reporting Standards (IFRS), os quais vêm sendo internalizados pelo Comitê de Pronunciamentos Contábeis - CPC e pelas normas emitidas pelos órgãos reguladores?

Sendo assim, o objetivo geral deste estudo foi o de investigar se o tratamento físcal instituído pela Lei $\mathrm{n}^{\circ} 12.973 / 2014$ para o IRPJ e a CSLL manteve neutra a tributação do lucro no quinquênio de 2015 a 2019 na comparação o quinquênio de 2010 a 2014, em que vigorou 
o RTT, com foco nas companhias listadas no cadastro aberto da Comissão de Valores Mobiliários (CVM, 2020), divididas em setores econômicos, sendo que a carga tributária foi calculada por intermédio da alíquota tributária efetiva (ETR, effective tax rate).

O cálculo da alíquota tributária efetiva (ETR) efetuado nesta pesquisa para a aferição da carga tributária combinou as metodologias long-run effective tax rate (CashETR), ETR corrente (ETRc) e ETR total (ETRt), uma vez que as variáveis foram mensuradas em períodos de cinco anos, considerando as despesas correntes e totais do IRPJ e da CSLL. Destarte, as variáveis quantificadas foram aqui denominadas de CashETRc e CashETRt, as quais dizem respeito às cargas tributárias corrente e total incidentes sobre o LAIR, respectivamente.

Com base no referencial teórico, não se esperava verificar diferenças estatisticamente significativas entre as CashETRt calculadas nos quinquênios de 2015 a 2019 e 2010 a 2014 para as companhias dos setores não financeiros (comércio, indústria, serviços e exploração de imóveis). A razão disso é que as adições e exclusões estabelecidas pela Lei $\mathrm{n}^{\circ}$ 12.973/2014 objetivaram a neutralidade na cobrança do IRPJ e da CSLL, de maneira que se supôs que as variações na tributação corrente do lucro seriam contrabalanceadas pela realização de ativos fiscais diferidos e/ou pela liquidação de passivos fiscais diferidos.

Contrariamente, em virtude da ampliação do rol das diferenças temporárias pela Lei $\mathrm{n}^{\circ}$ 12.973/2014 este estudo considerava como possível a ocorrência de variações estatisticamente significativas entre as CashETRc das companhias dos setores não financeiros (comércio, indústria, serviços e exploração de imóveis) calculadas nos quinquênios comparados.

Além disso, era esperado que as variáveis CashETRc e CashETRt das companhias do setor financeiro (bancos, seguradoras e outros serviços congêneres) tivessem sofrido aumento sob a vigência da Lei $\mathrm{n}^{\circ}$ 12.973/2014 haja vista a majoração das alíquotas da CSLL para essas pessoas jurídicas de $15 \%$ para $20 \%$ no período de setembro de 2015 a dezembro de 2018 , de acordo o disposto nas Leis $\mathrm{n}^{\circ} 11.727 / 2008$ e $\mathrm{n}^{\circ}$ 13.269/2015.

Assim, foram testadas as hipóteses nulas $\mathrm{H}_{1}$ e $\mathrm{H} 2_{0}$, abaixo enunciadas juntamente com as hipóteses alternativas $\mathrm{H} 2_{1}$ e $\mathrm{H} 1_{1}$ :

a) Hipótese Nula $\mathrm{H}_{0}$ : não houve diferença estatisticamente significativa entre as CashETRt do quinquênio de 2015 a 2019 (vigência da Lei $\mathrm{n}^{\circ}$ 12.973/2014) na comparação com as CashETRt do quinquênio de 2010 a 2014 (vigência do RTT).

b) Hipótese Alternativa $\mathrm{H}_{1}$ : houve diferença estatisticamente significativa entre as CashETRt do quinquênio de 2015 a 2019 (vigência da Lei $\mathrm{n}^{\circ}$ 12.973/2014) na comparação com as CashETRt do quinquênio de 2010 a 2014 (vigência do RTT).

c) Hipótese Nula $\mathrm{H} 2_{0}$ : não houve diferença estatisticamente significativa entre as CashETRc do quinquênio de 2015 a 2019 (vigência da Lei $n^{\circ}$ 12.973/2014) na comparação com as CashETRc do quinquênio de 2010 a 2014 (vigência do RTT).

d) Hipótese Alternativa $\mathrm{H} 2{ }_{1}$ : houve diferença estatisticamente significativa entre as CashETRc do quinquênio de 2015 a 2019 (vigência da Lei $n^{\circ}$ 12.973/2014) na comparação com as CashETRc do quinquênio de 2010 a 2014 (vigência do RTT).

O trabalho visou contribuir para o aprofundamento dos estudos da área de política tributária voltados ao aperfeiçoamento da legislação fiscal federal, no sentido de identificar eventuais aumentos na carga tributária incidente sobre lucro que pudessem ser atribuídos à adoção dos padrões internacionais de contabilidade pelas empresas brasileiras.

A pesquisa inovou na metodologia utilizada para a aferição da carga tributária do IRPJ e da CSLL posto que as variáveis CashETRt e CashETRc fossem quantificadas e comparadas 
em períodos quinquenais, em análise que buscou mensurar os efeitos das despesas correntes e diferidas relacionadas aos tributos, dada as características específicas da sistemática fiscal imposta pela Lei $n^{\circ} 12.973 / 2014$, vigente a partir de $1^{\circ}$ de janeiro de 2015.

\section{REFERENCIAL TEÓRICO}

Inicia-se o referencial teórico pelas pesquisas anteriores sobre a ETR.

\subsection{Pesquisas anteriores sobre a ETR}

A proxy mais adequada para a mensuração do nível de tributação do lucro empresarial seria uma alíquota tributária marginal (MTR, marginal tax rate) capaz de quantificar o montante do tributo incidente sobre cada unidade monetária adicional de renda auferida (POHLMANN; IUDÍCIBUS, 2010; PLESKO, 2003). Grupta e Newberry (1997) entendem que a alíquota tributária média (ATR, average tax rate) é uma forma de mensuração da carga tributária adequada para a comparação entre empresas e/ou setores econômicos. Da mesma forma, Lopes (2012) considera a ATR útil como métrica na comparação de contribuintes, sobretudo em razão da dificuldade de se estimar os custos tributários implícitos. De fato, o cálculo da ATR pode ser realizado a partir das informações financeiras divulgadas pelas companhias sediadas no País, bastando, para tal, dividir o valor das provisões correntes ou totais pelo lucro contábil do período, que no caso do Brasil é o Lucro antes do Imposto de Renda - LAIR, ponto de partida para a determinação da base de cálculo que sofrerá a incidência do IRPJ e da CSLL.

Deve-se observar que uma alíquota tributária efetiva (ETR) ou alíquota tributária média (ATR) não deve ser confundida com a alíquota tributária legal (LTR, legal tax rate), ou seja, a alíquota nominal prevista em lei, incidente sobre o lucro apurado para fins fiscais. No

Brasil, com exceção do setor financeiro (bancos, seguradoras ou outros), as pessoas jurídicas estão submetidas a uma LTR de $34 \%$, sendo $15 \%$ para o IRPJ, mais o adicional de $10 \%$, e $9 \%$ para a CSLL (RECEITA FEDERAL DO BRASIL, 2017).

Janssen (2000) sustenta que as métricas utilizadas no cálculo de uma alíquota tributária efetiva dependem da questão de pesquisa a ser respondida, ou seja, do objetivo do pesquisador. Nesse sentido, a ETR tem sido utilizada como métrica em estudos científicos nacionais e internacionais em diversas abordagens específicas. Três dessas abordagens são relevantes para este artigo, a saber: (i) pesquisas acerca da carga tributária suportada por firmas e/ou setores econômicos, em que a ETR é a variável dependente ou o critério comparativo (SANTOS; CAVALCANTE; RODRIGUES, 2013; CABELLO; PEREIRA, 2015; GUIMARÃES; MACEDO; CRUZ, 2016; CABEDA; FARIAS, 2019; RODRIGUES; GALDI, 2020); (ii) pesquisas que objetivaram aferir o nível de gestão ou agressividade tributária (MARTINEZ; RAMALHO, 2014; GOMES, 2016; SILVA, 2018; OLIVEIRA JR.; MOREIRA; SOUZA, 2020; HARTMANN; MARTINEZ, 2020); e (iii) pesquisas sobre a estrutura de capital das empresas, nas quais a ETR foi utilizada como variável explicativa (BASTOS; NAKAMURA, 2009; FUTEMA; BASSO; KAYO, 2009; POHLMANN; IUDÍCIBUS, 2010; MOREIRA; SILVA, 2019).

Analisando o comportamento de empresas listadas na B3 entre os anos de 2009 a 2013, Martinez e Motta (2020) buscaram identificar se a influência do controle estatal nas 
sociedades de economia mista (seis controladas pelo governo federal e 19 por governos estaduais), em comparação com empresas de controle privado (291 companhias), resultaria em variação quanto ao nível de gestão tributária, concluindo que as primeiras apresentaram uma ETR mais elevada, o que indicaria uma menor agressividade fiscal.

Rodrigues e Galdi (2020) perscrutaram os dados relativos aos anos de 2010 a 2015 de 500 empresas de capital aberto, em confronto com os dados de 498 empresas de capital fechado, para concluir que as empresas fechadas possuem um ETR maior que as demais. Em outra abordagem, Hartmann e Martinez (2020) concluíram que companhias auditadas por grandes empresas de auditoria (Big 4) apresentam agressividade tributária inferior às empresas que se utilizam de outras auditorias.

Em estudo voltado para identificar o efeito da governança tributária sobre o custo de capital de uma amostra de 60 empresas brasileiras no período de 2012 a 2016, com uso de painel de dados pooled, Moreira e Silva (2019, p. 18) concluíram que a variável independente ETR não apresentou significância estatística para explicar o custo de capital próprio das empresas analisadas, enquanto a variável CashETR apresentou significância positiva, indicando que "quanto maior for a alíquota efetiva de tributos analisada no longo prazo, maior é o retorno exigido pelos investidores na aplicação dos recursos". Ainda sob o enfoque da governança corporativa, Gomes (2016) observou as ETR e CashETR de 355 empresas de capital aberto nos anos de 2008 a 2014 para concluir que a remuneração variável oferecida aos executivos influencia na gestão tributária das empresas.

Cabello e Pereira (2015) concluíram que a combinação entre o setor de atividade econômica e as práticas contábeis adotadas explica estatisticamente a variância das ETR. A pesquisa abrangeu uma amostra de 250 empresas em 2009 e 272 empresas em 2010, para as quais foram calculadas as ETR correntes, em análise estatística realizada a partir de modelo linear geral. As práticas contábeis testadas incluíram o pagamento de juros sobre o capital próprio (JCP), a reorganização societária e incentivos fiscais para o IRPJ e a CSLL.

Santos, Cavalcante e Rodrigues (2013) verificaram que o endividamento e o tamanho do ativo são as variáveis econômicas independentes que mais influenciaram o ETR corrente, em estudo abrangendo 565 firmas no período de 1997 a 2011, realizada mediante teste de significância de coeficientes. Constataram, ainda, que as ETR correntes médias apresentaram redução no período de 2008 a 2011, passando de 8,52\% em 2008 e 2009 para 6,88\% em 2010 e 2011 (vigência do RTT).

Os fatores determinantes da ETR incidente sobre empresas de economias emergentes foram apontados por Fernándes-Rodriguez, Garcia-Fernández e Martínez-Arias (2020), que analisaram dados dos anos de 2006 a 2015 de 7844 empresas de capital aberto localizadas nos países componentes do BRICS (Brasil, Rússia, Índia, China e África do Sul) e do MINT (México, Indonésia, Nigéria e Tunísia), considerando ainda fatores institucionais característicos de cada um desses países (LTR, nível de desenvolvimento, índice de liberdade econômica, produto interno bruto e qualidade das instituições).

Os efeitos do Regime Transitório de Tributação - RTT foram objetos do estudo realizado por Guimarães, Macedo e Cruz (2016) que analisaram a alíquota efetiva dos tributos no período de 2003 a 2013, mensurada pela ETR total (ETRt) e a ETR corrente (ETRc), concluindo que os ajustes contábeis decorrentes desse regime resultaram em carga tributária menor na comparação com o regime anterior. No mesmo sentido, Cabeda e Farias (2019), ao analisarem 2.037 empresas no período de 2008 a 2018, identificou tendência de redução das ETR correntes a partir do início da vigência da Lei $n^{\circ}$ 12.973/2014, situação que os autores não constataram no período do RTT. Foi verificado, ainda, que as medianas das ETR 
correntes obtidas a partir das informações financeiras consolidadas das empresas resultaram superiores àquelas calculadas com base nas informações individuais.

\subsection{A utilização da ETR para aferir a carga tributária imposta pela legislação do IRPJ e da CSLL}

Embora a ETR tenha por objetivo estabelecer uma relação entre o lucro e os impostos sobre ele incidentes, não há na literatura consenso quanto à melhor metodologia a ser empregada em seu cálculo (SANTOS; CAVALCANTE; RODRIGUES, 2013; RICHARDSON; LANIS, 2007; CALLIHAN, 1994). A questão se coloca, fundamentalmente, pela existência de disposições na legislação tributária que permitem tanto diferir parte do tributo, para pagamento em períodos subsequentes, como compensar prejuízos pretéritos nas bases de cálculo. Nesse sentido, as limitações do uso da ETR para aferir o desempenho de empresas brasileiras em termos de lucro por ação e índice preço/lucro foi destacada por Carvalho et al. (2017).

De acordo com o Pronunciamento Técnico CPC 32 de 2009, a despesa ou provisão corrente para o IRPJ e a CSLL mensura a carga tributária incidente sobre o lucro tributário do período. Ocorre que a legislação do IRPJ e da CSLL impõe ou permite o diferimento para fins tributários de um conjunto específico de receitas, custos e despesas, bem como a possibilidade de compensação futura de bases de cálculo negativas e outros benefícios fiscais, dando origem a ativos e passivos fiscais diferidos, a serem realizados ou liquidados em períodos futuros. Ativo fiscal diferido é o tributo recuperável em períodos futuros, oriundo de diferença temporária dedutível, de compensação de prejuízo fiscal do IRPJ ou base negativa da CSLL ou de outros benefícios fiscais. Já passivo fiscal diferido é o tributo devido sobre o lucro de período futuro originado de uma diferença temporária tributável (CPC, 2009).

Assim, nos tributos correntes deduzidos do LAIR não são computados os ativos fiscais diferidos realizados no período, relativos a diferenças temporárias dedutíveis verificadas em períodos anteriores, com exceção das compensações de prejuízos fiscais e bases negativas ou outros benefícios fiscais, como isenções ou reduções de base de cálculo. Também não são incluídos no montante dos tributos correntes os passivos fiscais diferidos liquidados no período, concernentes a diferenças temporárias tributáveis escrituradas em períodos anteriores (CPC, 2009).

No sentido de minimizar os efeitos desses diferimentos fiscais, Guimarães, Macedo e Cruz (2016) propõem, para fins de análise dos tributos incidentes sobre o lucro no Brasil, o cálculo de uma alíquota tributária efetiva total (ETRt), a partir da divisão entre o valor integral da despesa com o IRPJ e a CSLL pelo lucro apurado antes da constituição de provisão para pagamento desses tributos (LAIR), e de uma alíquota tributária efetiva corrente (ETRc), que utilizaria apenas a despesa corrente daqueles tributos na divisão pelo LAIR. Santos, Cavalcante e Rodrigues (2013) defendem que a ETR deve ser calculada mediante o tributo corrente deduzido no resultado do período, porquanto expressa o valor que deverá ser pago sobre o lucro do período, em decorrência direta das adições e exclusões exigidas ou permitidas na legislação do IRPJ e da CSLL.

Também no sentido de minimizar os efeitos da transferência de ativos e passivos fiscais de um exercício para outro, Moreira e Silva (2019), em estudo voltado para a governança tributária, propõem uma abordagem de longo prazo para cálculo da alíquota tributária efetiva, a ser obtida a partir da medição da ETR corrente por um período não inferior a dez anos, ou seja, uma long-run cash effective tax rate (CashETR). A mesma 
abordagem viria a ser utilizada por Oliveira Jr., Moreira e Souza (2020) para analisar a alíquota efetiva de tributos em empresas de energia elétrica listadas na B3.

Sendo o objetivo da utilização da ETR a quantificação do nível de tributação incidente sobre o LAIR, não faz sentido mensurá-la em períodos nos quais foi apurado prejuízo contábil ou resultado igual a 0 (zero). Assim, a ETR não deve ser calculada quando não há LAIR positivo (CABELLO; PEREIRA, 2015; SANTOS; CAVALCANTE; RODRIGUES, 2013; POHLMANN; IUDÍCIBUS, 2010).

Ademais, os prejuízos fiscais do IRPJ e bases negativas da CSLL verificados no período não devem ser incluídos no numerador das ETR (CABELLO; PEREIRA, 2015; POHLMANN; IUDÍCIBUS, 2010). A justificativa é que os prejuízos fiscais e as bases negativas são ativos diferidos realizáveis apenas por intermédio de compensação com as bases de cálculo apuradas em períodos futuros. $\mathrm{O}$ cômputo de provisões positivas no numerador da fórmula das ETR pode gerar inconsistências na aferição da carga tributária em interstícios maiores que um ano, posto que os créditos fiscais levantados em cada período de apuração podem ser utilizados na redução do IRPJ e da CSLL recolhidos a partir do período seguinte. Para fins da quantificação da carga tributária, é mais adequado reconhecer os benefícios econômicos desses créditos fiscais apenas no momento de sua efetiva compensação, o que implica a redução das despesas correntes e/ou diferidas de períodos futuros. É importante salientar que os prejuízos fiscais do IRPJ e as bases negativas da CSLL são compensáveis até o limite de $30 \%$ do LAIR ajustado pelas adições e exclusões do período, de acordo com os artigos 15 e 16 da Lei $\mathrm{n}^{\circ}$ 9.065/1995.

\subsection{Os efeitos esperados da Lei $\mathbf{n}^{0} \mathbf{1 2 . 9 7 3 / 2 0 1 4}$ sobre as ETR}

Os Anexos I e II da Instrução Normativa RFB n 1.700, de 14 de março de 2017, na redação dada pela Instrução Normativa RFB no 1.881, de 3 de abril de 2019, discriminam a lista de adições e exclusões aplicáveis ao regime do lucro real no IRPJ e na CSLL. Em análise ao Anexo I anteriormente referido, verifica-se que das 202 espécies de adições ali identificadas, $107(53 \%)$ se relacionam com o regramento fiscal estabelecido pela Lei $\mathrm{n}^{\circ}$ 12.973/2014. Por seu turno, no Anexo II da mencionada normativa observa-se que dos 144 tipos de exclusões ali elencadas, $80(55,5 \%)$ dizem respeito a regras estatuídas pela Lei $\mathrm{n}^{\circ}$ 12.973/2014. Tal informação extraída da própria legislação tributária denota uma significativa ampliação do rol de diferenças entre os lucros contábil e fiscal a partir do ano de 2015.

Em exame aos textos da Lei $n^{\circ} 12.973 / 2014$ e da Instrução Normativa RFB $n^{\circ}$ 1.700/2017, verificou-se que seus dispositivos criaram novas espécies de diferenças temporárias com o objetivo de conferir tratamento tributário, neutralizando para fins fiscais: a) o ajuste a valor presente; b) o ajuste a valor justo; c) os arrendamentos mercantis; d) a redução ao valor recuperável dos ativos (impairment); e) o imobilizado e o intangível, inclusive os custos de desmontagem, a depreciação e a amortização; f) os investimentos em coligadas e controladas; g) as combinações de negócios, inclusive o tratamento fiscal ao goodwill, à mais-valia e às demais parcelas; h) as concessões de serviços públicos; (i) as doações e subvenções do poder público; (j) os prêmios na emissão de debêntures; (k) os pagamentos baseados em ações; (l) as propriedades para investimento; (m) os juros de empréstimos; (n) as despesas com emissões de instrumentos de capital e ou de dívida subordinada; (o) as adoções iniciais do ajuste de avaliação patrimonial, do ativo diferido, de ativos relacionados aos contratos de concessão de serviços públicos, de diferenças em ativos e passivos de controladas; e (p) outros métodos ou critérios contábeis posteriores à publicação da Lei $\mathrm{n}^{\mathrm{o}}$ 12.973/2014, de acordo com a regra prevista em seu art. 58 (SILVA; SANTOS; 
KOGA; BARBOSA, 2014). Por outro lado, observou-se que as diferenças permanentes criadas pela Lei $\mathrm{n}^{\circ} 12.973 / 2014$ foram poucas e específicas, a exemplo das variações cambiais dos saldos a apropriar dos ajustes a valor presente ou das despesas incorridas na emissão de ações.

Destarte, os ajustes fiscais criados pela Lei $\mathrm{n}^{\circ}$ 12.973/2014 alteraram a legislação do IRPJ e da CSLL por meio de uma significativa ampliação do rol das diferenças temporárias existentes entre os lucros contábil e tributário, reconhecidas na escrituração como ativos ou passivos fiscais diferidos (CPC, 2009). Essas diferenças temporárias ocorrem em razão do período em que são reconhecidas as receitas ou despesas para fins da apuração dos resultados contábil e tributário, ou ainda das distintas bases de mensuração utilizadas na contabilidade e na apuração dos tributos (HENDRIKSSEN; BREDA, 2010).

Por definição, as ETR variam de acordo com as alterações nos montantes das provisões correntes ou totais para o IRPJ e a CSLL (numerador) e no lucro antes dos tributos (LAIR) (denominador), ocorridas durante o período de aferição da carga tributária. Nesse sentido, é importante ressaltar que a maioria dos novos métodos ou critérios contábeis neutralizados pela Lei $\mathrm{n}^{\circ} 12.973 / 2014$ para fins tributários surtem efeitos tanto sobre as provisões correntes e diferidas, quanto sobre o LAIR.

O Quadro 1 indica os principais fatos contábeis que são causadores de diferenças temporárias ou permanentes no IRPJ e na CSLL e os seus efeitos as ETR corrente e total (ETRc e ETRt). Tais conclusões foram obtidas em conformidade com o Pronunciamento Técnico CPC 32 de 2009, a legislação tributária (Decreto $\mathrm{n}^{\circ} 3.000$, de 26 de março de 1999, Decreto $n^{\circ}$ 9.580, de 22 de novembro de 2018 e Instrução Normativa RFB $n^{\circ} 1.700 / 2017$ ) e Santos (2015).

Quadro 1 - Fatos contábeis causadores de diferenças temporárias ou permanentes no IRPJ e CSLL e seus efeitos sobre as ETRc e ETRt

\begin{tabular}{|c|c|c|c|c|c|}
\hline Fatos Contábeis & $\begin{array}{c}\text { Tipo de } \\
\text { Diferença }\end{array}$ & $\begin{array}{c}\text { Tratamento } \\
\text { Contábil }\end{array}$ & $\begin{array}{c}\text { Tratamento } \\
\text { Fiscal } \\
\text { (IRPJ/CSLL) }\end{array}$ & $\begin{array}{c}\text { Efeito sobre a } \\
\text { ETR corrente }\end{array}$ & $\begin{array}{c}\text { Efeito sobre a } \\
\text { ETR total }\end{array}$ \\
\hline $\begin{array}{c}\text { Receita auferida } \\
\text { no período, } \\
\text { diferida para fins } \\
\text { fiscais }\end{array}$ & Temporária & $\begin{array}{c}\text { Reconhecimento } \\
\text { de passivo fiscal } \\
\text { diferido }\end{array}$ & Exclusão & $\begin{array}{c}\text { Pode aumentar } \\
\text { ou reduzir a } \\
\text { ETRc. Provoca } \\
\text { aumento na } \\
\text { provisão para os } \\
\text { tributos } \\
\text { correntes e no } \\
\text { LAIR }\end{array}$ & $\begin{array}{c}\text { Pode aumentar } \\
\text { ou reduzir a } \\
\text { ETRt. Provoca } \\
\text { aumento na } \\
\text { provisão para os } \\
\text { tributos } \\
\text { correntes e no } \\
\text { LAIR }\end{array}$ \\
\hline $\begin{array}{c}\text { Receita auferida } \\
\text { no período, não } \\
\text { tributável pelo } \\
\text { IRPJ/CSLL }\end{array}$ & Permanente & Não há & Exclusão & $\begin{array}{c}\text { Reduz a ETRc. } \\
\text { Não altera as } \\
\text { provisões } \\
\text { corrente ou } \\
\text { diferida, no } \\
\text { entanto aumenta } \\
\text { o LAIR }\end{array}$ & $\begin{array}{c}\text { Reduz a ETRt. } \\
\text { Não altera as } \\
\text { provisões } \\
\text { corrente ou } \\
\text { diferida, no } \\
\text { entanto aumenta } \\
\text { o LAIR }\end{array}$ \\
\hline
\end{tabular}




\begin{tabular}{|c|c|c|c|c|c|}
\hline $\begin{array}{l}\text { Receita auferida } \\
\text { em períodos } \\
\text { anteriores, } \\
\text { reconhecida para } \\
\text { fins fiscais } \\
\text { durante o período }\end{array}$ & Temporária & $\begin{array}{l}\text { Liquidação do } \\
\text { passivo fiscal } \\
\text { diferido }\end{array}$ & Adição & $\begin{array}{l}\text { Efeito neutro. } \\
\text { Não altera a } \\
\text { provisão } \\
\text { corrente nem o } \\
\text { LAIR }\end{array}$ & $\begin{array}{c}\text { Aumenta a } \\
\text { ETRt. Provoca } \\
\text { aumento na } \\
\text { provisão } \\
\text { diferida, mas } \\
\text { não altera o } \\
\text { LAIR }\end{array}$ \\
\hline $\begin{array}{l}\text { Custo ou despesa } \\
\text { do período, } \\
\text { diferido para fins } \\
\text { fiscais }\end{array}$ & Temporária & $\begin{array}{c}\text { Reconhecimento } \\
\text { de ativo fiscal } \\
\text { diferido }\end{array}$ & Adição & $\begin{array}{l}\text { Pode aumentar } \\
\text { ou reduzir a } \\
\text { ETRc. Provoca } \\
\text { diminuição na } \\
\text { provisão } \\
\text { corrente e no } \\
\text { LAIR }\end{array}$ & $\begin{array}{c}\text { Pode aumentar } \\
\text { ou reduzir a } \\
\text { ETRt. Provoca } \\
\text { diminuição na } \\
\text { provisão } \\
\text { corrente e no } \\
\text { LAIR }\end{array}$ \\
\hline $\begin{array}{l}\text { Custo ou despesa } \\
\text { do período, } \\
\text { indedutível no } \\
\text { IRPJ/CSLL }\end{array}$ & Permanente & Não há & Adição & $\begin{array}{c}\text { Aumenta a } \\
\text { ETRc. Não } \\
\text { causa alteração } \\
\text { nas provisões } \\
\text { corrente ou } \\
\text { diferida, mas } \\
\text { diminui o LAIR }\end{array}$ & $\begin{array}{c}\text { Aumenta a } \\
\text { ETRt. Não } \\
\text { causa alteração } \\
\text { nas provisões } \\
\text { corrente ou } \\
\text { diferida, mas } \\
\text { diminui o LAIR }\end{array}$ \\
\hline $\begin{array}{l}\text { Custo ou despesa } \\
\text { incorridos em } \\
\text { períodos } \\
\text { anteriores, } \\
\text { reconhecido para } \\
\text { fins fiscais no } \\
\text { período }\end{array}$ & Temporária & $\begin{array}{l}\text { Realização do } \\
\text { ativo fiscal } \\
\text { diferido }\end{array}$ & Exclusão & $\begin{array}{l}\text { Efeito neutro. } \\
\text { Não altera a } \\
\text { provisão } \\
\text { corrente nem o } \\
\text { LAIR }\end{array}$ & $\begin{array}{l}\text { Diminui a } \\
\text { ETRt. Provoca } \\
\text { redução na } \\
\text { provisão } \\
\text { diferida, mas } \\
\text { não altera o } \\
\text { LAIR }\end{array}$ \\
\hline $\begin{array}{l}\text { Prejuízo fiscal do } \\
\text { IRPJ e/ou base } \\
\text { negativa da } \\
\text { CSLL de } \\
\text { períodos } \\
\text { anteriores } \\
\text { compensado no } \\
\text { período }\end{array}$ & Permanente & $\begin{array}{c}\text { Realização do } \\
\text { ativo fiscal } \\
\text { diferido }\end{array}$ & Compensação & $\begin{array}{c}\text { Reduz a ETRc. } \\
\text { Causa } \\
\text { diminuição nas } \\
\text { provisões } \\
\text { corrente e/ou } \\
\text { diferida, no } \\
\text { entanto não } \\
\text { altera o LAIR }\end{array}$ & $\begin{array}{c}\text { Reduz a ETRt. } \\
\text { Causa } \\
\text { diminuição nas } \\
\text { provisões } \\
\text { corrente e/ou } \\
\text { diferida, no } \\
\text { entanto não } \\
\text { altera o LAIR }\end{array}$ \\
\hline
\end{tabular}

Fonte: preparado pelos autores

\section{MÉTODO}

De acordo com Marconi e Lakatos (2017), o presente estudo é de natureza descritiva, tendo sido realizado sob a técnica da pesquisa documental. A metodologia utilizada é mista, pois envolveu uma investigação qualitativa, complementada por outra, quantitativa. Conforme Creswell (2010) a metodologia mista é uma abordagem de investigação que combina as formas qualitativa e quantitativa, sendo a primeira um meio de explorar ou entender o significado atribuído a problemas sociais; e a segunda um meio de testar teorias objetivas examinando a relação entre variáveis. 
Segundo a classificação proposta por Pohlmann e Iudícibus (2006) para as pesquisas tributárias, este estudo é do tipo teórico-empírico porquanto abrange um trabalho teórico e outro empírico (DEMO, 1985 apud POHLMANN \& IUDÍCIBUS, 2006). A metodologia utilizada foi empírico-arquival, também denominada de pesquisa de arquivo, uma vez que a coleta dos dados foi realizada a partir das demonstrações financeiras divulgadas pelas companhias incluídas na população estudada. A temática da pesquisa pode ser classificada em duas linhas propostas por Pohlmann e Iudícibus (2006), a saber, tributação ótima e eficiência econômica dos tributos; e pesquisa legal, do tipo jurídico-tributária.

Na pesquisa quantitativa foi aferida a neutralidade da Lei ${ }^{\circ} 12.973 / 2014$ mediante o cálculo das cargas tributárias corrente e total no quinquênio de 2015 a 2019 e sua comparação com o quinquênio de 2010 a 2014 (RTT), utilizando o teste estatístico não-paramétrico de Wilcoxon para verificar se a variação ocorrida foi estatisticamente significativa nas companhias pesquisadas, divididas em setores econômicos.

Foram incluídas na população de pesquisa as sociedades anônimas listadas no cadastro aberto da Comissão de Valores Mobiliários (CVM, 2020), inclusive as que atualmente se encontram com o registro de companhia aberta cancelado. Houve a exclusão das companhias que, no período de 2010 a 2019: a) não apresentaram as Demonstrações Financeiras Padronizadas - DFP; b) não auferiram receita líquida superior a $\mathrm{R} \$ 78$ milhões, em qualquer dos anos-calendário; c) foram extintas, por qualquer motivo; e d) a atividade tenha sido unicamente a participação em outras sociedades (holdings puras). Segundo esses parâmetros, verificou-se, inicialmente, um total de 228 companhias.

Considerando o objetivo de mensurar a carga tributária durante os regimes do RTT e da Lei $\mathrm{n}^{\mathbf{0}}$ 12.973/2014, e em vista das divergências metodológicas verificadas na literatura, a variável ETR foi calculada neste estudo sob método que combinou as características do longrun effective tax rate (CashETR), da ETR total (ETRt) e da ETR corrente (ETRc). Assim, as duas variáveis ETR mensuradas nesta pesquisa foram aqui denominadas de CashETRc e CashETRt, dizendo respeito às cargas tributárias total e corrente do IRPJ e da CSLL, respectivamente.

Quanto aos períodos de mensuração, as CashETRt e CashETRc foram quantificadas para os quinquênios 2015 a 2019 (vigência da Lei no 12.973/2014) e 2010 a 2014 (vigência do RTT). Em cada um dos referidos períodos de cinco anos, as CashETRt foram calculadas incluindo-se, no numerador, as despesas correntes e diferidas do IRPJ e da CSLL e, paralelamente, as CashETRc foram apuradas considerando-se apenas as despesas correntes desses tributos.

As companhias foram divididas nos seguintes setores de atividade econômica: não financeiro, subdividido em comércio, indústria, serviços e exploração de imóveis; e financeiro, o qual incluiu os bancos, as seguradoras e outros serviços congêneres. Os critérios utilizados para divisão das companhias em setores foram dois, a saber: o tipo de atividade operacional preponderante da companhia e suas controladas; e a alíquota da CSLL, a qual é diferenciada para as pessoas jurídicas atuantes no setor financeiro.

No cálculo das CashETRt e CashETRc foram computados apenas os LAIR positivos e as provisões para o IRPJ e a CSLL negativas. Foram excluídas da população as companhias que não apresentaram LAIR positivo em nenhum dos anos abrangidos pelos períodos quinquenais. Chegou-se então a um quantitativo final de 207 companhias.

Os cálculos das CashETRt e CashETRc tomaram por base as informações financeiras consolidadas divulgadas nas Demonstrações Financeiras Padronizadas - DFP, com referência 
ao período de 2010 a 2019. As fórmulas utilizadas para o cálculo das CashETRt e CashETRc nos quinquênios de 2010 a 2014 e de 2015 a 2019, ver Quadro 2, fórmulas.

Quadro 2 - Fórmulas das CashETRt e CashETRc nos quinquênios de 2015 a 2019 e 2010 a 2014

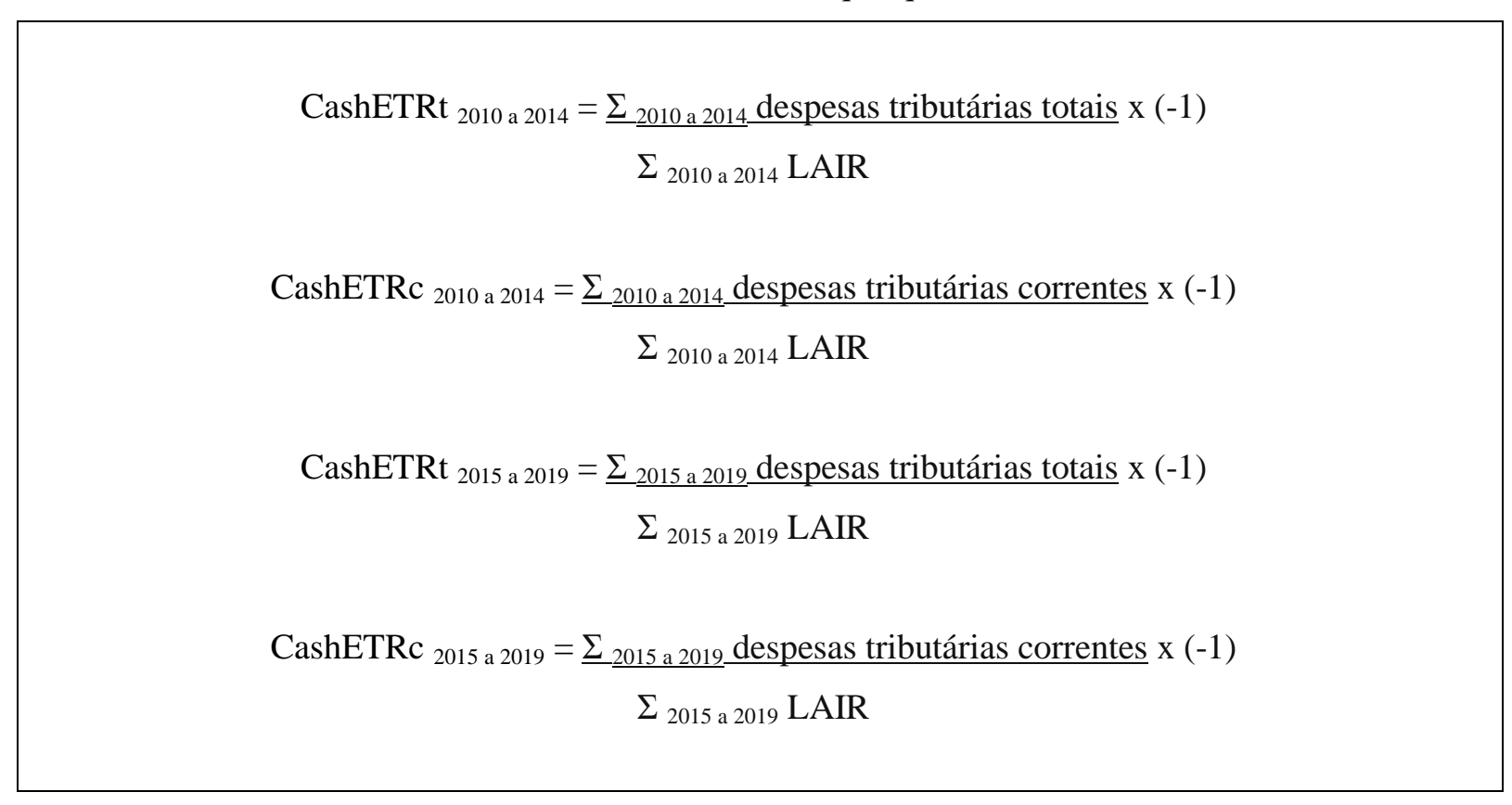

Fonte: preparado pelos autores

O objetivo da mensuração da variável CashETRc foi o de verificar se o aumento do número de ajustes de adição e exclusão pela Lei $n^{\circ} 12.973 / 2014$ a partir do ano de 2015 implicou em variação na tributação corrente incidente sobre o LAIR. Já a variável CashETRt foi utilizada por ser mais adequada para quantificar a carga tributária total que efetivamente recaiu sobre o LAIR, haja vista que considera não só as despesas correntes, mas também as diferidas.

A distribuição normal das amostras de CashETRt e CashETRc foi aferida pelo teste de Kolmogorov-Smirnov. Foi aplicado o teste não-paramétrico de Wilcoxon para analisar se as companhias pertencentes aos setores apresentaram variação estatisticamente significativa nas CashETRt e nas CashETRc entre os quinquênios comparados.

Segundo Martins e Domingues (2017) o teste de Wilcoxon possui a mesma natureza do teste dos Sinais, que analisa dados emparelhados, sendo o mesmo indivíduo submetido a duas medidas, antes e depois. Porém, os autores esclarecem que aquele teste se distingue metodologicamente porquanto leva em consideração a magnitude da diferença verificada em cada par de variáveis. A hipótese nula assume que a mediana das diferenças das variáveis emparelhadas na população é igual a zero (FÁVERO; BELFIORE, 2020). Foi utilizado o software SPSS - IBM para a realização dos mencionados testes estatísticos.

Uma vez aplicado o teste de Wilcoxon, a hipótese nula $\mathrm{H} 1_{0}$ foi aceita para os setores econômicos que apresentaram p-value superior a 0,05 para as CashETRt emparelhadas de suas companhias, concluindo-se pela inexistência de diferença estatisticamente significativa entre as cargas tributárias totais incidentes sobre o LAIR, mensuradas nos quinquênios comparados. 
Por seu turno, a hipótese nula $\mathrm{H} 2_{0}$ foi retida no caso dos setores econômicos que apresentaram $p$-value maior que 0,05 para as CashETRc emparelhadas, de modo a se concluir que não houve diferença estatisticamente significativa no nível de tributação corrente do lucro quantificado nos quinquênios abrangidos pela pesquisa.

Destarte, a aceitação das hipóteses nulas $\mathrm{H} 1_{0}$ e $\mathrm{H} 2_{0}$ implicou a conclusão de que o tratamento fiscal instituído pela Lei $\mathrm{n}^{\mathrm{o}} 12.973 / 2014$ foi neutro na comparação com o RTT, relativamente ao IRPJ e à CSLL. Contudo, no caso da rejeição das hipóteses nulas $\mathrm{H} 1_{0}$ e $\mathrm{H} 2_{0}$ não haveria informações suficientes para sustentar que o regime da Lei $n^{\circ} 12.973 / 2014$ foi a única causa das variações estatisticamente significativas verificadas nos níveis de tributação total e/ou corrente do lucro das companhias.

No setor financeiro, a retenção das hipóteses nulas $\mathrm{H}_{1}$ e $\mathrm{H} 2_{0}$ acarretou a conclusão de que o tratamento tributário instituído pela Lei $\mathrm{n}^{\circ}$ 12.973/2014 foi neutro em relação ao RTT, muito embora as alíquotas da CSLL tenham sido majoradas a partir de 2015. Todavia, a rejeição das hipóteses nulas $\mathrm{H}_{0}$ e $\mathrm{H} 2_{0}$ poderia indicar que essa majoração das alíquotas da CSLL surtiu efeitos sobre a carga tributária das companhias, no caso em que tenha ocorrido aumento nas CashETRt e CashETRc entre os quinquênios.

\section{RESULTADOS E DISCUSSÃO}

Iniciam-se os resultados e discussão pela estatística descritiva.

\subsection{Estatística Descritiva}

As medianas das variáveis CashETRt e das CashETRc verificadas nos setores não financeiro (comércio, indústria, serviços e exploração de imóveis) e no setor financeiro (bancos e outros) estão indicados na Tabela 1, relativamente aos quinquênios de 2010 a 2014 e 2015 a 2019.

Tabela 1 - Medianas das CashETRt e CashETRc nos setores de atividade econômica, nos quinquênios comparados

\begin{tabular}{ccccc}
\hline \multirow{2}{*}{ Setor / Estatística /Quinquênio } & \multicolumn{2}{c}{ Mediana - CashETRt } & \multicolumn{2}{c}{ Mediana - CashETRc } \\
\cline { 2 - 5 } & $\begin{array}{c}\text { Quinquênio } \\
2010 \text { a } 2014\end{array}$ & $\begin{array}{c}\text { Quinquênio } \\
2015 \text { a } 2019\end{array}$ & $\begin{array}{c}\text { Quinquênio } \\
2010 \text { a } 2014\end{array}$ & $\begin{array}{c}\text { Quinquênio } \\
2015 \text { a } 2019\end{array}$ \\
\hline $\begin{array}{c}\text { Setor Não Financeiro } \\
\text { (187 Companhias })\end{array}$ & $26,7 \%$ & $26,6 \%$ & $23,3 \%$ & $23,7 \%$ \\
\hline $\begin{array}{c}\text { Comércio } \\
\text { (17 Companhias) }\end{array}$ & $28,1 \%$ & $23,6 \%$ & $29,1 \%$ & $29,0 \%$ \\
\hline $\begin{array}{c}\text { Indústria } \\
\text { (75 Companhias) }\end{array}$ & $23,1 \%$ & $23,1 \%$ & $18,9 \%$ & $21,1 \%$ \\
\hline Serviços & $29,1 \%$ & $29,5 \%$ & $25,8 \%$ & $26,2 \%$ \\
\hline
\end{tabular}


(88 Companhias)

\begin{tabular}{ccccc}
\hline $\begin{array}{c}\text { Exploração de Imóveis } \\
(7 \text { Companhias })\end{array}$ & $22,9 \%$ & $27,7 \%$ & $13,3 \%$ & $18,0 \%$ \\
\hline $\begin{array}{c}\text { Setor Financeiro } \\
(20 \text { companhias })\end{array}$ & $29,6 \%$ & $26,4 \%$ & $36,2 \%$ & $31,4 \%$ \\
\hline $\begin{array}{c}\text { Bancos } \\
(12 \text { Companhias })\end{array}$ & $25,0 \%$ & $23,8 \%$ & $36,2 \%$ & $30,4 \%$ \\
\hline $\begin{array}{c}\text { Outras } \\
(8 \text { Companhias })\end{array}$ & $34,0 \%$ & $30,3 \%$ & $34,6 \%$ & $31,5 \%$ \\
\hline
\end{tabular}

Fonte: preparado pelos autores

Observa-se que os setores comercial e financeiro apresentaram uma redução nas medianas da variável CashETRt no quinquênio de 2015 a 2019, o que indica a ocorrência de um decréscimo na carga tributária total incidente sobre o LAIR. Contrariamente, as medianas da variável CashETRt apontaram para um acréscimo na carga tributária total nos setores de serviços e de exploração de imóveis, relativamente ao quinquênio iniciado em 2015. Não foi verificada alteração no setor industrial.

Já as medianas da variável CashETRc apontam para a ocorrência de um incremento da tributação corrente nos setores industrial, de serviços e de exploração de imóveis no quinquênio de 2015 a 2019. Por outro lado, as medianas da variável CashETRc sugerem um decréscimo na carga tributária corrente das companhias financeiras, que ficou muito próxima da estabilidade no setor comercial.

Muito embora as alíquotas nominais da CSLL para o setor financeiro tenham sido majoradas pela Lei $\mathrm{n}^{\circ} 13.169$ de 2015 a partir de setembro de 2015 até dezembro de 2018 - o percentual nominal médio dos quinquênios se elevou de 15\% (2010 a 2014) para 18,33\% (2015 a 2019) -, verificou-se uma redução significativa nas medianas das variáveis CashETRt e CashETRc mensuradas naquele setor, o que se observa tanto no caso dos bancos quanto dos outros serviços financeiros.

\subsection{Testes de Kolmogorov-Smirnov e de Wilcoxon}

A normalidade das variáveis CashETRt e CashETRc foi rejeitada pelo teste de Kolmogorov-Smirnov, tendo o $p$-value resultado em 0,0000 nas quatro amostras quinquenais relativas às companhias: CashETRc 2015 a 2019, CashETRc 2010 a 2014, CashETRt 2015 a 2019 e CashETRt 2010 a 2014.

Os resultados obtidos no teste de Wilcoxon para as variáveis emparelhadas CashETRt e CashETRc nos quinquênios de 2015 a 2019 (Lei no 12.973/2014) e 2010 a 2014 (RTT), calculadas para as companhias incluídas na pesquisa, divididas em setores de atividade econômica, com base nas informações financeiras consolidadas, ver Tabela 2. 
Tabela 2 - Teste de Wilcoxon para as variáveis CashETRt e CashETRc emparelhadas

\begin{tabular}{|c|c|c|c|c|}
\hline \multirow{2}{*}{ Setores } & \multicolumn{2}{|c|}{$\begin{array}{c}\text { Sig. }(P-\text { Value }) \text { do Teste de } \\
\text { Wilcoxon }\end{array}$} & \multirow{2}{*}{$\begin{array}{l}\mathrm{N}^{\circ} \text { de Pares } \\
\text { Observados }\end{array}$} & \multirow{2}{*}{ Conclusão } \\
\hline & CashETRt & CashETRc & & \\
\hline $\begin{array}{l}\text { Não Financeiro (todas } \\
\text { as Cias, exceto as do } \\
\text { setor financeiro) }\end{array}$ & 0,841 & 0,096 & 187 & $\begin{array}{l}\text { Reter as hipóteses nulas } \\
\qquad \mathrm{H} 1_{0} \text { e } \mathrm{H} 2_{0} .\end{array}$ \\
\hline Comércio & 0,687 & 0,287 & 17 & $\begin{array}{c}\text { Reter as hipóteses nulas } \\
\qquad \mathrm{H} 1_{0} \text { e } \mathrm{H} 2_{0} .\end{array}$ \\
\hline Indústria & 0,796 & 0,285 & 75 & $\begin{array}{l}\text { Reter as hipóteses nulas } \\
\qquad \mathrm{H} 1_{0} \text { e } \mathrm{H} 2_{0} .\end{array}$ \\
\hline Serviços & 0,789 & 0,352 & 88 & $\begin{array}{l}\text { Reter as hipóteses nulas } \\
\qquad \mathrm{H} 1_{0} \text { e } \mathrm{H} 2_{0} .\end{array}$ \\
\hline Exploração de Imóveis & 0,310 & 0,237 & 7 & $\begin{array}{c}\text { Reter as hipóteses nulas } \\
\qquad \mathrm{H} 1_{0} \text { e } \mathrm{H} 2_{0} .\end{array}$ \\
\hline $\begin{array}{l}\text { Financeiro (bancos, } \\
\text { seguradoras e outros) }\end{array}$ & 0,028 & 0,021 & 20 & $\begin{array}{l}\text { Rejeitar as hipóteses } \\
\text { nulas } \mathrm{H} 1_{0} \text { e } \mathrm{H} 2_{0} \text {. }\end{array}$ \\
\hline
\end{tabular}

Fonte: preparado pelos autores

Nas companhias do setor financeiro as hipóteses nulas $\mathrm{H} 1_{0}$ e $\mathrm{H} 2_{0}$ foram rejeitadas porquanto os $p$-value resultaram inferiores a 0,05 , de forma que foi confirmada a ocorrência de variação estatisticamente significativa nas cargas tributárias total e corrente no quinquênio de 2015 a 2019 relativamente ao período de 2010 a 2015.

Porém, o que mais chamou a atenção foi que a variação observada nas CashETRt e CashETRc a partir de 2015 não foi no sentido do aumento das cargas tributárias. Contrariamente ao esperado, os números mostraram uma redução das CashETRc e CashETRt emparelhadas em 14 das 20 companhias pesquisadas do setor financeiro (bancos, seguradoras e outros serviços congêneres), muito embora tenha ocorrido a majoração das alíquotas nominais da CSLL, de $15 \%$ para 20\%, de setembro de 2015 a dezembro de 2018.

\section{CONSIDERAÇÕES FINAIS}

Nos setores não financeiros - comércio, indústria, serviços e exploração de imóveis o teste de Wilcoxon demonstrou a inexistência de diferença estatisticamente significativa para as variáveis CashETRt e CashETRc nos quinquênios comparados, o que implicou a retenção das hipóteses nulas $\mathrm{H} 1_{0}$ e $\mathrm{H} 2_{0}$, ao nível de significância de $5 \%$. A partir dessa constatação, a conclusão é a de que o regime fiscal da Lei no 12.973/2014 foi neutro na tributação do IRPJ e da CSLL na comparação com o Regime Tributário de Transição - RTT, não tendo sido obtida 
evidência estatística de alteração nas cargas tributárias total ou corrente calculadas nas companhias pesquisadas, entre os quinquênios de 2015 a 2019 e 2010 a 2014.

É de se notar que os $p$-value da variável CashETRc resultaram menores que os $p$-value da variável CashETRt em todos os setores. Isso indica que as variações na tributação total incidente sobre o lucro foram menores do que as correspondentes variações correntes, conforme era esperado dado o aumento do rol de diferenças temporárias a partir da vigência da pela Lei $\mathrm{n}^{\mathrm{o}} 12.973 / 2014$, em $1^{\circ}$ da janeiro de 2015 . Ao nível de significância de $10 \%$, seria possível concluir que a variável CashETRc apresentou diferença estatisticamente significativa entre os quinquênios não só nas 20 companhias do setor financeiro ( $p$-value $=0,021)$, mas também nas 187 das companhias classificadas no setor não financeiro ( $p$-value $=0,096$ ).

No setor financeiro foi constatada uma redução estatisticamente significativa das cargas tributárias total e corrente no período de 2015 a 2019, comparativamente com o quinquênio anterior, em que pese tenha havido a majoração das alíquotas nominais da CSLL de $15 \%$ para $20 \%$, no período de setembro de 2015 a dezembro de 2018.

O presente trabalho não identificou qualitativamente as causas das variações ocorridas na carga tributária incidente sobre o lucro das companhias, vinculadas a diferenças permanentes ou temporárias não instituídas pela Lei $\mathrm{n}^{\circ} 12.973 / 2014$, tais como as compensações de prejuízos fiscais ou bases negativas da CSLL, as isenções tributárias e as adições e exclusões já previstas da legislação anteriormente a 2015.

Espera-se com este artigo contribuir para o aprofundamento do estudo da legislação do IRPJ e da CSLL no regime do lucro real, compulsoriamente aplicado às pessoas jurídicas com receita bruta superior a $\mathrm{R} \$ 78$ milhões por ano, especialmente no que toca à efetiva neutralidade desse regime diante dos novos métodos e critérios contábeis normatizados nos pronunciamentos técnicos, interpretações e orientações do CPC, convergentes com o padrão dos IFRS.

Sugere-se a realização de pesquisas complementares com o objetivo de ratificar o decréscimo no nível de tributação do lucro verificado nas companhias do setor financeiro no período de 2015 a 2019, bem como de identificar as causas dessas variações, relacionando-as, ou não, com o regime fiscal do IRPJ e da CSLL estabelecido pela Lei no 12.973/2014.

\section{REFERÊNCIAS}

BASTOS, D. D.; NAKAMURA, W. T. Determinantes da estrutura de capital das companhias abertas no Brasil, México e Chile no período 2001-2006. Revista de Contabilidade \& Finanças - USP, São Paulo, v. 20, n. 50, p. 75-94, maio/ago. 2009.

BRASIL. Decreto-Lei $\mathbf{n}^{\circ}$ 1.598, de 26 de dezembro de 1977. Disponível em: <DEL1598 (planalto.gov.br)>. Acesso em: 07 dez. 2020.

BRASIL. Decreto $\mathbf{n}^{\mathbf{0}}$ 3.000, de 26 de março de 1999. Disponível em: <D3000 (planalto.gov.br)>. Acesso em: 07 dez. 2020.

BRASIL. Decreto $\mathbf{n}^{\mathbf{9}}$ 9.580, de 22 de novembro de 2018. Disponível em: <D9580 (planalto.gov.br)>. Acesso em: 07 dez. 2020.

BRASIL. Lei $\mathbf{n}^{0}$ 6.404, de 15 de dezembro de 1976. Disponível em: <L6404consol (planalto.gov.br)>. Acesso em: 07 dez. 2020. 
BRASIL. Lei $\mathrm{n}^{\circ}$ 11.638, de 28 de dezembro de 2007. Disponível em: <Lei $\mathrm{n}^{\mathrm{o}} 11.638$ (planalto.gov.br)>. Acesso em: 07 dez. 2020.

BRASIL. Lei no 11.941, de 27 de maio de 2009. Disponível em: <L11941 (planalto.gov.br)〉. Acesso em: 07 dez. 2020.

BRASIL. Lei no 12.973, de 13 de maio de 2014. Disponível em: 〈L12973 (planalto.gov.br)〉. Acesso em: 07 dez. 2020.

CABEDA, Diogo. A taxa tributária efetiva e a neutralidade fiscal nas empresas de capital aberto no Brasil: um estudo a partir da adoção das normas internacionais de contabilidade e da Lei $\mathbf{n}^{\mathbf{0}}$ 12.973/2014. Dissertação (Mestrado em Controladoria e Contabilidade) - Faculdade de Ciências Econômicas, Universidade Federal do Rio Grande do Sul, Porto Alegre, 2020.

CABELLO, O. G. Análise dos efeitos das práticas de tributação do lucro na Effective Tax Rate (ETR) das companhias abertas brasileiras: uma abordagem da teoria das escolhas contábeis. Tese (Doutorado em Controladoria e Contabilidade) - Faculdade de Economia, Administração e Contabilidade, Universidade de São Paulo. São Paulo, 2012.

CALLIHAN, D. S. Corporate Effective Tax Rate: A Synthesis of Literature. Journal of Accounting Literature. Vol. 13, 1994, p. 1-43.

CARVALHO, Valdemir Galvão et al. Limitações da effective tax rate na mensuração do desempenho das companhias brasileiras. RIC - Revista de Informação Contábil. Recife, vol. 11, núm. 1, janeiro-março, 2017, p. 56-75. 2017.

COMISSÃO DE VALORES MOBILIÁRIOS. Portal Dados Abertos CVM, 2020. Cias Abertas: Informação Cadastral. Disponível em: < Cias Abertas: Informação Cadastral Conjuntos de dados - Portal Dados Abertos CVM>. Acesso em: 29 ago. 2020.

COMISSÃO DE VALORES MOBILIÁRIOS. Portal Dados Abertos CVM, 2020. Cias Abertas: Documentos: Formulário de Informações Trimestrais. Disponível em: < Cias Abertas: Documentos: Formulário de Informações Trimestrais (ITR) - Conjuntos de dados Portal Dados Abertos CVM>. Acesso em: 29 ago. 2020.

COMITÊ DE PRONUNCIAMENTOS CONTÁBEIS. Pronunciamento Técnico CPC 32, de 17 de julho de 2009. Disponível em: < Pronunciamento (cpc.org.br)>. Acesso em: 25 ago. 2020.

CRESWELL, John W. Projeto de pesquisa: métodos qualitativo, quantitativo e misto. 3 ed. Porto Alegre: Artmed, 2010.

FÁVERO, Luiz Paulo; BELFIORE, Patrícia. Manual de Análise de Dados. 1 ed. Rio de Janeiro: LTC, 2020.

FERNANDES, Edison Carlos. Nascimento, vida e morte do Regime Tributário de Transição - RTT. In: MOSQUERA, Roberto Quiroga; LOPES, Alexsandro Broedel. Controvérsias Jurídico-contábeis: aproximações e distanciamentos. $3^{\circ}$ vol. São Paulo: Dialética, 2012.

FERNANDEZ-RODRÍGUES, Elena; GARCÍA-FERNÁNDEZ， Roberto; MARTÍNEZARIAS, Antonio. Business and Institutional Determinants of Effective Tax Rate in Emerging Economies. Economic Modelling, Elsevier Journals, v. 94, jan. 2021, p. 692-702.

FUTEMA, Mariano Seikitsi; BASSO, Leonardo Fernando Cruz; KAYO, Eduardo Kazuo. Estrutura de capital, dividendos e juros sobre o capital próprio: testes no Brasil. Revista Contabilidade \& Finanças, São Paulo, v. 20, n. jan/abr. 2009, p. 44-62, 2009. 
GOMES, Antônio Paulo Machado. Características da governança corporativa como estímulo à gestão fiscal. Revista Contabilidade e Finanças - USP, São Paulo, vol. 27, num. 71, maioagosto, 2016, pp. 149-168. 2016.

GUIMARÃES, Guilherme Otávio Monteiro; MACEDO, Marcelo Álvaro da Silva; CRUZ, Cláudia Ferreira da. Análise da alíquota efetiva de tributos sobre o lucro no Brasil< um estudo com foco na RTRt e na ETRc. Enfoque: Reflexão Contábil. Maringá, vol. 35, núm. 1, janeiro-abril, 2016, p. 1-16. 2016.

GUPTA, Sanjay, NEWBERRY, Kaye. Determinants of the variability in corporate effective tax rates: evidence from longitudinal study. Journal of Accounting and Public Policy. [S.1.], p. 1-34, 1997.

HARTMANN, Carla Furtado; MARTINEZ, Antonio Lopo. Agressividade fiscal e as empresas de auditoria Big4. REUNIR: Revista de Administração, Ciências Contábeis e Sustentabilidade. [S.I], vol. 10, n. 3, 2020, p. 37-46. 2020.

HENDRIKSEN, Eldon S.; BREDA Michael F. V. Teoria da Contabilidade. São Paulo: Atlas, 2010.

JANSSEN, Boudewijn. (2000). Effective tax rate (ETR) measures: alternatives and their validity. MARC Working Papers, 2000.

LOPES, Tatiana. Custos Políticos Tributários: O Impacto de Tamanho na Alíquota Tributária Efetiva. Doutorado em Ciências Contábeis. Universidade de São Paulo. São Paulo, 2012.

MARCONI, Marina de Andrade; LAKATOS, Eva Maria. Metodologia Científica. 7 ed. São Paulo: Atlas, 2017.

MARTINEZ, Antônio Lopo; MOTTA, Fábio Pereira. Tax agressiveness of governmentcontrolled corporations in Brazil. Revista Contemporânea de Contabilidade. Florianópolis, vol. 17, núm. 43, abril-junho, 2020, p. 136-148. 2020.

MARTINEZ, Antônio Lopo; RAMALHO, G. C. Family Firms and Tax Aggressiveness in Brazil. International Business Research, v. 7, n. 3, p. 129-136, 2014.

MARTINS, Gilberto de Andrade; DOMINGUES, Osmar. Estatística Geral e Aplicada. 6 ed. São Paulo: Atlas, 2017.

MOREIRA, Caritsa Scartati; SILVA, Maurício Corrêa. O efeito da governança tributária sobre o custo de capital das empresas brasileiras. Revista Científica Hermes. [N.I], vol. 23, 2019, p. 3-27. 2019.

OLIVEIRA JÚNIOR, Elton Gomes de; MOREIRA, Caritsa Scartaty; SOUZA, Jocykleber Meirelles de. Cash effective tax rate (CashETR) para determinação da relação entre o lucro e gerenciamento tributário: análise das empresas de energia elétrica da B3. Revista de Administração da Faculdade Estácio do Pará. Belém, vol. 7, núm. 13, junho, 2020, pp. 124-137. 2020.

PLESKO, George A. An Evaluation of alternative measure of corporate tax rates. Journal of

Accounting and Economics, v. 35, p. 201-226, 2003.

POHLMANN, Marcelo Coleto; IUDÍCIBUS, Sérgio. Relação entre Tributação do Lucro e a Estrutura de Capital das Grandes Empresas no Brasil. Revista Contabilidade \& Finanças - USP, v. 21, n. 53, p. 1-25, 2010. 
POHLMANN, Marcelo Coleto; IUDÍCIBUS, Sérgio. Tributação e Política Tributária Uma Abordagem Multidisciplinar. 1 ed. São Paulo: Atlas, 2006.

RECEITA FEDERAL DO BRASIL. Instrução Normativa RFB no 1.700 , de 14 de março de 2017. Disponível em:< IN RFB No 1700 - 2017 (fazenda.gov.br)>. Acesso em: 15 set. 2020.

RICHARDSON, Grant; LANIS, Roman. Determinants of the variability in corporate effective tax rate and tax reform: Evidence from Australia. Journal of Accounting and Public Policy. Vol. 26. Issue 6. November-December 2007. pp. 689-704. 2007.

RODRIGUES, Dinamar Vidallas; GALDI, Fernando Caio. Taxa de imposto efetiva nas empresas brasileiras: uma comparação entre empresas abertas e fechadas. Revista Contemporânea de Contabilidade. Florianópolis, vol. 17, núm. 42, janeiro-março, 2020, pp. 57-69. 2020.

SANTOS, Mateus Alexandre Costa dos. Contabilidade Tributária Um enfoque nos IFRS e na Legislação do IRPJ. São Paulo: Atlas, 2015.

SANTOS, Mateus Alexandre Costa dos; CAVALCANTE, Paulo Roberto Nóbrega; RODRIGUES, Raimundo Nonato. Tamanho da firma e outros determinantes da tributação efetiva sobre o lucro no brasil. Advances in Scientific and Applied Accounting ASAA, v. 6, n. 2, p. 179-210, 2013.

SILVA, Cláudia Lúcia Pimentel Martins da; SANTOS, Mateus Alexandre Costa dos; KOGA, Gilson Hiroyuki; BARBOSA, Ricardo Antônio Carvalho. Tributação e IFRS no Brasil: Alterações na Legislação do IRPJ, CSLL, PIS/PASEP e da COFINS, Trazida pela Lei N ${ }^{\circ}$ 12.973/2014. Revista da Receita Federal. v. 1. n. 1. Ago/Dez 2014. p. 393-422. 2014. 